\title{
HUBUNGAN PENGETAHUAN DAN SIKAP IBU TERHADAP PENGGUNAANKB METODE KONTRASEPSI JANGKA PANJANG (MKJP) DI WILAYAH KERJA PUSKESMAS PARAMASAN KABUPATEN BANJAR, MARTAPURA (Judul
}

(Relationship Of Women's Knowledge And Attitudes To Use Of Kb Long-Term Contraception (MKJP) Method In Working Areas Puskesmas Paramasan Kabupaten Banjar, Martapura)

\author{
Ari Widyarni, Siska Dhewi
}

\begin{abstract}
Fakultas Kesehatan Masyarakat Universitas Islam Kalimantan (UNISKA) MAB Banjarmasin
Email: ariwidyarnifkm@gmail.com
\end{abstract}

\begin{abstract}
ABSTRAK
Kabupaten Banjar, Martapura masih termasuk dalam wilayah dimana cakupan KB MKJP rendah, dapat dilihat pada angka capaian yang menunjukkan penurunan signifikan pada tahun 2015 mencapai 6,6\%, pada tahun 2016 mencapai 7,0\% dan pada tahun 2017 hanya 2,3\%. Penelitian ini adalah penelitian kuantitatif dengan pendekatan Cross Sectional. Populasi dan sampel adalah ibu dengan kriteria wanita usia subur (WUS) sebagai akseptor keluarga berencana yang mengunjungi dan mencari perawatan di Puskesmas Paramasan Kabupaten Banjar. Besar sampel berjumlah 60 responden. Data dikumpulkan dengan wawancara menggunakan kuesioner terstruktur, hasil pengumpulan data dianalisis menggunakan statistik univariat dan bivariat dengan uji Chi Square Test menggunakan program komputer dengan nilai signifikansi (a) 0,05. Hasil analisis univariat menunjukkan bahwa sebagai besar responden tidak menggunakan KB MKJP, sebagian besar responden memiliki pengetahuan yang cukup dan sebagian besar sikap responden cukup. Analisis bivariat menunjukkan hasil bahwa ada hubungan pengetahuan terhadap penggunaan KB MKJP ( $p$-value $=0,001)$ dan ada hubungan sikap terhadap penggunaan $K B$ MKJP ( $p$-value $=0,000$ ). Direkomendasikan bagi instansi terkait untuk meingkatkan kerja sama lintas sektor dalam upaya meningkatkan pengetahuan dan sikap responden tentang kelebihan dan kekurangan menggunakan KB MKJP. Diharapkan dengan meningkatnya pengetahuan yang dimiliki oleh responden tentang KB MKJP, maka sikap responden dalam penggunaan kontrasepsi untuk KB MKJP diharapkan menjadi lebih baik. Dan akan mempengaruhi peningkatan jumlah penggunaan MKJP KB.
\end{abstract}

Kata kunci : Pengetahuan, Sikap, WUS, KB MKJP.

\begin{abstract}
Kabupaten Banjar, Martapura are still included in the regions where the coverage of MKJP KB is low, it can be seen in the achievement figures which show a significant decrease in 2015 reached 6.6\%, in year 2016 reached $7.0 \%$ and in year 2017 , only $2.3 \%$. This research is a quantitative study with a cross sectional approach. The population and sample are mothers with criteria for women of childbearing age (WUS) as family planning acceptors who visit and seek treatment at Puskesmas Paramasan Kabupaten Banjar. A large sample of 60respondents. Data was collected by interview using a structured questionnaire, the results of data collection were analyzed using univariate and bivariate statistics with a chi square test using a computer program with a significance value $(\alpha) \leq 0.05$. The results of the univariate analysis showed that the majority of respondents did not use MKJP KB, most of the respondents had sufficient knowledge and most respondents' attitudes were sufficient. Bivariate analysis showed that there was a correlation between knowledge of the use of MKJP KB (p-value $=0.001)$ and there was a relationship between attitudes towards the use of MKJP KB ( $p$-value $=0.000)$.It is recommended for agencies to be concerned about the need for cross-sector cooperation in an effort to increase respondents' knowledge and attitudes about the advantages and disadvantages of using MKJP KB.It is expected that with the increased knowledge held by respondents about MKJP KB, then the attitude of respondents in contraceptive use for KB MKJP is expected to be better.And will affect the increase in the number of MKJP KB use.
\end{abstract}

Keywords : Knowledge, Attitude, WUS, KB MKJP 


\section{PENDAHULUAN}

Metode Kontrasepsi Jangka Panjang (MKJP) adalah jenis kontrasepsi yang sangat efektif untuk menghindari kelahiran, mengatur interval kelahiran dan tidak mempengaruhi hubungan seksual yang dapat bertahan selama 3 Tahun sampai seumur hidup, seperti: IUD, Implant, MOW dan MOP. Metode MKJP seperti AKDR, Kontap, dan Implat dianggap lebih efektif dan lebih mantap dibandingkan dengan alat kontrasepsi pil,kondom maupun suntik sehingga akseptor sesuai dengan syarat-syarat yang ada dianjurkan untuk menggunakan salah satu dari MKJP yang ada. Pada saat ini alat kontrasepsi jangka panjang terutama AKDR/IUD merupakan salah satu cara kontrasepsi yang paling popular dan diterima oleh program keluarga berencana disetiap Negara (BKKBN, 2011).

Indonesia merupakan Negara yang dilihat dari jumlah penduduknya ada pada posisi keempat di dunia, dengan laju pertumbuhan yang relative tinggi. Esensitugas program Keluarga Berencana (KB) dalam hal ini telah jelas yaitu menurunkan fertilitas agar dapat mengurangi beban pembangunan demi terwujudnya kebahagiaan dan kesejahteraan bagi rakyat dan bangsa Indonesia. Pelayanan program KB pelaksanaannya senantiasa terintegrasi dengan kegiatan kelangsungan hidup ibu, bayi dan anak serta penanggulangan masalah kesehatan dan kesetaraan gender sebagai salah satu upaya pemecahan hak-hak reproduksi kepada masyarakat.

Rencana pembangunan jangka panjang tahun 2005-2025 adalah mendukung upaya penurunan Angka Kematian Ibu (AKI) dan Angka Kematian Bayi (AKB) yang masih cukup tinggi di Indonesia dibandingkan Negara ASEAN, kesepakatan Global (Millenium Developmen Goal ( MDG's 2020) pada tahun 2015 diharapkan AKI (2007) menurun dari 228 menjadi 102 per 100.000 kelahiran hidup (2015) dan AKB (2007) dari 34 menurun menjadi 23 per 1000 kelahiran hidup (2015).(Kementrian Kesehatan RI, 2012)

Tingginya angka kelahiran juga merupakan alasan utama diperlukannya pelayanan keluarga berencana. Banyak perempuan mengalami kesulitan di dalam menentukan pilihan jenis kontrasepsi. Hal ini tidak hanya karena terbatasnya metode yang tersedia tetapi juga oleh ketidaktahuan mereka tentang persyaratan dan keamanan penggunaan metode kontrasepsi tersebut.Metode kontrasepsi jangka panjang (MKJP) terbukti paling efektif untuk menekan angka kehamilan, namun hingga saat ini MKJP masih belum menjadi pilihan mayoritas pasangan usia subur di Indonesia. Jenis MKJP seperti IUD, Implant dan sterilisasi berupa vasektomi dan tubektomi telah terbukti secara ilmiah sebagai metode paling efektif menjarangkan kehamilan. Sayangnya pengguna MKJP di Indonesia kalah jauh dari metode pil KB dan suntik KB.(Affandi, 2011)

Survey Demografi Kesehatan Indonesia (SDKI ) 2010-2012, menunjukkan bahwa 62\% wanita kawin usia 15-49 tahun menggunakan alat KB metode kontrasepsi modern $58 \%$ dan 4\% menggunakan metode tradisional.Di antara KB modern metode yang banyak digunakan suntik KB $32 \%$ diikuti pil $14 \%$, AKDR 4,8\%, susuk 2,8\%, tubektomi $3,1 \%$ dan kondom $1,3 \%$. Hal ini terkait dengan tingginya angka putus pemakaian pada metode jangka pendek sehingga perlu pemantauan yang terus menerus. Disamping itu pengelolaan program KB perlu memfokuskan sasaran pada kategori pasangan usia subur (PUS) dengan 4 terlalu (terlalu muda, tua, sering dan banyak). Data AKI yang terjadi akibat melahirkan terlalu tua dan terlalu mudasebesar $32,5 \%$ dan akibat kehamilan yang terlalu banyak atau lebih dari tiga anak sebesar 34\%.(BPS, 2013)

Kabupaten Banjar masih termasuk dalam daerah yang cakupan KB MKJPnya rendah, terlihat dari capaian KB MKJP dari tahun 2015 sampai dengan 2017, tetapi pada tahun 2017 mengalami penurunan yang signifikan yaitu baru tercapai $2.3 \%$, sedangkan pada tahun 2015 tercapai $6.6 \%$ dan tahun 2016 tercapai $7.0 \%$. Kontrasepsi jangka panjang yang masih dominan digunakan para Akseptor adalah Implant yaitu sebesar $3.84 \%$ dan IUD sebesar $1.12 \%$. Hasil Mini Survei yang dilakukan oleh Dinas P2KBP3A menunjukkan metode KB hormonal yaitu suntik dan pil merupakan metode yang paling dominan digunakan oleh peserta KB.Beberapa faktor yang menyebabkan Akseptor KB tidak mau untuk memilih kontrasepsi dengan metode jangka panjang adalah dukungan suami, belum meratanya promosi dan KIE yang menjangkau seluruh lapisan masyarakat sehingga mempengaruhi pengetahuan peserta Akseptor, anggapan miring dari masyarakat tentang kontrasepsi jangka panjang, ketakutan dari Akseptor sendirimengenai proses penggunaan KB MKJP dan meningkatnya kampanye penggunaan kontrasepsi hormonal (pil dan suntik) 
oleh swasta (produk andalan). (Dinas P2KBP3A, 2015-2017)

Berdasarkan latar belakang tersebut, penelitian ini perlu dilakukan mengenai "Hubungan pengetahuan dan sikap Ibu terhadap penggunaan KB Metode Kontrasepsi Jangka Panjang di wilayah kerja Puskesmas Paramasan Kabupaten Banjar Martapura".

\section{BAHAN DAN METODE}

Penelitian ini merupakan penelitian Survey Kuantitatif dengan pendekatan Cross Sectional yaitu desain penelitian yang meneliti suatu titik waktu dimana variable independen yaitu pengetahuan dan sikap ibu sedangkan variable dependen penggunaan KB metode kontrasepsi jangka panjang (MKJP) diteliti sekaligus pada saat yang sama (point time aproach). Populasi dalam penelitian ini adalah seluruh ibu dengan kriteria WUS sebagai akseptor KB yang berkunjung dan berobat di Puskesmas Paramasan Kabupaten Banjar berjumlah 154ibu WUS. Pengambilan sampel pada penelitian inisecara accidental sampling yaitu pengambilan sampel secara aksidental dengan mengambil responden sebagai akseptor KB yang berkunjung dan berobat di Puskesmas Paramasan Kabupaten Banjar sebesar 60 responden.

Pengolahan dan analisis data menggunakan analisis univariat dan bivariat uji statistikChi Square test, derajat kepercayaan 95 $\%$ dengan alat bantu program komputer. Kriteria Ho ditolak apabila $p$-value $\leq 0,05$ berarti ada hubungan yang bermakna secara statistik dan sebaliknya apabila $p$-value $>0,05$ maka Ho diterima yang berarti tidak ada hubungan yang bermakna secara statistik.(Sugiyono, 2015)

\section{HASIL DAN PEMBAHASAN}

\section{a. Analisis Univariat}

Tabel 1.Distribusi Frekuensi Berdasarkan Pengetahuan, Sikap dan Penggunaan KB MKJP Responden

\begin{tabular}{|c|c|c|}
\hline Variabel & $\mathbf{N}$ & $\%$ \\
\hline \multicolumn{3}{|l|}{ Pengetahuan } \\
\hline Kurang & 9 & 15 \\
\hline Cukup & 36 & 60 \\
\hline Baik & 15 & 25 \\
\hline \multicolumn{3}{|l|}{ Sikap } \\
\hline Tidak Baik & 14 & 23 \\
\hline Cukup & 34 & 57 \\
\hline Baik & 12 & 20 \\
\hline $\begin{array}{l}\text { Penggunaan } \\
\text { MKJP }\end{array}$ & KB & \\
\hline Tidak & 33 & 55 \\
\hline Ya & 27 & 45 \\
\hline Jumlah & 60 & 100 \\
\hline
\end{tabular}

Sumber: Data Primer

Berdasarkan tabel 1 diketahui bahwa hasil distribusi frekuensi tingkat pengetahuan responden tentang KB MKJP menunjukkan sebagian besar responden memiliki pengetahuan yang cukup tentang KB MKJP yaitu sebesar 36 responden (60\%).Distribusi frekuensi sikap responden tentang KB MKJP menunjukkan sebagian besar responden memiliki sikap yang cukup tentang KB MKJP yaitu sebesar 34 responden (57\%). Distribusi frekuensi penggunaan KB MKJP responden menunjukkan sebagian besar responden tidak menggunakan KB MKJP yaitu sebesar 33 responden (55\%) dan sisanya sebanyak 27 responden (45\%) menggunakan KB MKJP yang berupa Implan

\section{Analisis Bivariat}

Hubungan Pengetahuan Terhadap Penggunaan KB MKJP

Tabel 2.Hubungan Pengetahuan Terhadap Penggunaan KB MKJP

\begin{tabular}{|c|c|c|c|c|c|c|c|}
\hline \multirow{3}{*}{ Pengetahuan } & \multicolumn{4}{|c|}{ Penggunaan KB MKJP } & \multirow{2}{*}{\multicolumn{2}{|c|}{ Total }} & \multirow{3}{*}{$p$-value } \\
\hline & \multicolumn{2}{|c|}{ Tidak } & \multicolumn{2}{|c|}{$Y a$} & & & \\
\hline & $\mathbf{N}$ & $\%$ & $\mathbf{n}$ & $\%$ & $\mathbf{n}$ & $\%$ & \\
\hline Kurang & 8 & 14 & 1 & 1 & 9 & 15 & \\
\hline Cukup & 23 & 38 & 13 & 22 & 36 & 60 & 0,001 \\
\hline Baik & 2 & 3 & 13 & 22 & 15 & 25 & \\
\hline Jumlah Responden & 33 & 55 & 27 & 45 & 60 & 100 & \\
\hline
\end{tabular}

Sumber: Data Primer

Table 2 menunjukan bahwa responden dengan pengetahuan kurang sebagian besar tidak menggunakan KB MKJP yaitu sebanyak 8 responden $(14 \%)$, selanjutnya pada responden dengan pengetahuan cukup sebagian besar juga 
tidak menggunakan KB MKJP yaitu sebanyak 23 responden $(38 \%)$, dan distribusi pengetahuan baiksebagian besar menggunakan KB MKJP yaitu sebanyak 13 responden (22\%). Responden yang baik pengetahuanya tetapi tidak menggunakan KB MKJP disebabkan karena responden takut dan malujika dipasang KB MKJP seperti IUD, implant dan MOW atau steril, selanjutnya responden yangberpengetahuan cukup tidak mau menggunakan KB MKJP karena kurang begitu paham dengan KBMKJP dan ada yang berdasarkan keyakinan dan bahkan ada yang dilarang oleh suaminya dan untukresponden yang berpengetahuan kurang dan tidak menggunakan KB MKJP itu juga karena kurang paham tentang KB MKJP dan terpengaruh oleh orang lain.

Hubungan Sikap Terhadap Pengunaan KB MKJP

Tabel 3. Hubungan Sikap terhadap penggunaan KB MKJP

\begin{tabular}{|c|c|c|c|c|c|c|c|}
\hline \multirow{3}{*}{ Sikap } & \multicolumn{4}{|c|}{ Penggunaan KB MKJP } & \multirow{2}{*}{\multicolumn{2}{|c|}{ Total }} & \multirow{3}{*}{ p-value } \\
\hline & \multicolumn{2}{|c|}{ Tidak } & \multicolumn{2}{|c|}{ Ya } & & & \\
\hline & $\mathbf{F}$ & $\%$ & $\mathbf{F}$ & $\%$ & $\mathbf{F}$ & $\%$ & \\
\hline Tidak baik & 13 & 22 & 1 & 2 & 14 & 24 & 0,000 \\
\hline Cukup & 17 & 28 & 17 & 28 & 34 & 56 & \\
\hline Baik & 3 & 5 & 9 & 26 & 12 & 20 & \\
\hline Jumlah Responden & 33 & 55 & 27 & 45 & 60 & 100 & \\
\hline
\end{tabular}

Sumber: Data Primer

Berdasarkan tabel 3. menunjukan bahwa responden yang mempunyai sikap baik dan menggunakan KB MKJP sebanyak 9 responden $(26 \%)$ lebih banyak dari pada responden yang bersikap baik dan tidak menggunakan KB MKJP yaitu sebanyak 3 responden(5\%). Sementara yang sikapnya tidak baik tetapi menggunakan KB MKJP hanya sejumlah1 responden (2\%) lebih sedikit dari pada yang sikap tidak baik dan tidak menggunakan KB MKJP yaitu sebanyak 13 responden $(22 \%)$. Sedikinya jumlah responden yang sikapnya baik tetapi menggunakan KB MKJP dikarenakan kurangnya dukungan responden dari suami dan adanya pengaruh dari orang lain untuk tidak menggunakan KB MKJP tersebut.

\section{PEMBAHASAN}

\section{Pengetahuan Tentang KB MKJP}

Pengetahuan responden tentang KB MKJP merupakan pemahaman responden tentang pengertian KB MKJP, macam KB MKJP, fungsi dan manfaat KB MKJP, penggunaan KB MKJP dan efek samping KB MKJP. Hasil Penelitian mengenai tingkat pengetahuan responden tentang KB MKJP di wilayah kerja Puskesmas Paramasan Kabupaten Banjar menunjukkan sebagian besar responden memiliki pengetahuan yang cukup, yaitu sebanyak 36 responden (60\%), salah satu dari penyebab pengetahuan cukup tersebut adalah dalam kuesioner pengetahuan terdapat beberapa pertanyaan mengenai KB secara umum dan spesifik KB MJKP, dimana pengetahuan tersebut mudah dipahami meskipun secara umum pengetahuan itu cukup namun dalam penelitian ini jugaditemukan responden yang pengetahuannya kurang yaitusebanyak 9 responden (15\%).Tingkat pengetahuan tentang KB MKJPtersebut dipengaruhi oleh adanya beberapa faktor pendukung pengetahuan yang ada disekitar responden antara lain pendidikan, pekerjaan dan umur(Wawan dan Dewi, 2010).

Sementara itu Mubarrak menyatakan bahwa secara umum pengetahuan seseorang dipengaruhi oleh pendidikan, pekerjaan, usia, minat, pengalaman hidup, budaya dan informasi. Pendidikan juga berperan penting dalam pembentukan kecerdasan manusia maupun perubahan tingkah lakunya. Pendidikan juga berarti bimbingan yang diberikan seseorang kepada orang lain terhadap sesuatu hal agar mereka dapat memahami. Tidak dapat dipungkiri bahwa semakin tinggi pendidikan seseorang maka semakin mudah pula mereka menerima informasi. Pada akhirnya banyak pula pengetahuan yang dimilikinya. Sebaliknya jika seseorang memiliki tingkat pendidikan yang rendah maka akan menghambat perkembangan sikap seseorang terhadap penerimaan informasi. (Mubarakdkk, 2009)

Berdasarkan tingkat pendidikan responden, menunjukkan bahwa sebagian besar responden memiliki pendidikan yang baik yaitu SLTA, dimana tingkat pendidikan dalam Undang-undang No. 23 tahun 2003 tentang Sistem Pendidikan Nasional, dinyatakan bahwa tingkat pendidikan menengah yaitu 9 tahun merupakan batas minimal tingkat pendidikan yang baik. Hal tersebut sebagaimana dikemukakan oleh Kusumaningrum yang 
menyatakan bahwa tingkat pendidikan yang dimilikimempunyai pengaruh kuat pada perilaku reproduksi dan penggunaan alat konterasepsi. Tingkatpendidikan responden tersebut tergolong baik yang mampu menopang kemampuan merekauntuk menangkap dan memahami informasi-informasi dari luar yang merupakan sumber pengetahuan tentang KB MKJP. Informasi-informasi tersebut diperoleh dari teman,petugas kesehatan, orang tua, media informasi, internet dan lain-lain.(Kusumaningrum, 2009)

\section{Sikap Tentang Penggunaan KBMKJP}

Sikap merupakan respon responden terhadap penggunaan KB MKJP, hasil penelitian mengenai sikap responden paling banyak sikap cukup yaitu sebesar 34 responden (56\%), sedangkan paling sedikit responden dengan sikap baik yaitu sebanyak 12 responden $(20 \%)$.

Sikap merupakan reaksi atau respon dari seseorang terhadap suatu stimulus atau objek, baik yang bersifat intern maupun ekstern sebagai manifestasinya tidak dapat langsung dilihat, tetapi hanya dapat ditafsirkan terlebih dahulu dari perilaku yang tertutup tersebut. Sikap tentang KB MKJP adalah reaksi responden tentang penggunaan KB MKJP sebagai salah satu alternatif penggunaan kontrasepsi. Dalam bukunyateori danpengukuran pengetahuan, sikap dan perilaku manusiamengemukakan faktorfaktor pembentuk sikap adalah kebudayaan, orang lain yang dianggap penting, media massa, institusi atau lembaga pendidikan, pengalaman pribadi dan faktor emosi dalam diri individu. (Wawan dan Dewi, 2010)

Niven melalui pendekatan pembelajara sosial menyebutkan bahwa pembentukan atau perubahan sikap orang dewasa terjadi melalui "terpaparnya" carabaru untuk melakukan suatu kegiatan melalui tindakan yang dilakukan oleh teman, rekan, kerja,orang tua atau saudara. (Niven, 2000)

Sikap responden tentang KB MKJP dipengaruhi oleh beberapa faktor, antara lain pengalaman pribadi, pengaruh orang yang dianggap penting, pengaruh kebudayaan dan media massa. Dalam kehidupan mereka, responden tentunya mengalami interaksi dengan lingkungan, baik lingkungan keluarga maupunlingkungan masyarakat. Interaksi tersebut akan menghasilkanadanya pengalaman tentang KB MKJP baik dari melihat secara langsung maupun dari cerita oranglain. Pengalaman- pengalaman tersebut dapat berupa tentang pengertian KB MKJP,efek samping KB MKJP, jenis KB MKJP dan dapat pula berupa sikap orang dalam memiliki KB MKJP. Pengalaman yang diterima responden khususnya tentang sikap penggunaan KB MKJP merupakan salah satu sumber atau referensi responden dalam menyikapi penggunaan KB MKJP.

\section{Penggunaan KB MKJP}

Penggunaan KB MKJP responden menunjukkan sebagian besar responden memilih tidak menggunakan KB MKJP sebesar 33 responden (55\%). Perilaku kesehatan pada dasarnya adalah suatu respon seseorang terhadap stimulus yang berkaitan dengan sakit dan penyakit, pada system pelayanan kesehatan, makanan serta lingkungan.(Mubarak, dkk. 2009)

Perilaku dapat diartikan sebagai kegiatan atau aktivitas seseorang atau organisasi yang bersangkutan. Penggunaan KB MKJP dalam penelitian ini adalah tindakan nyata responden dalam penggunaanKB MKJP. Tingkat penggunaan KB MKJP tersebut disebabkan adanya beberapa faktor yang mempengaruhi penggunaanKB MKJP respondenmisalnya: tingkat pendidikan, status sosial ekonomi dan pengaruh orang yang dipercaya.

Dalam (Wawan dan Dewi, 2009) menyebutkan ada empat faktor yang mempengaruhi perilaku hidup sehat yaitu motivasi, kemampuan, persepsi dan kepribadian. Motivasi adalah suatu kekuatan yang mendorong orang berperilaku tertentu. Kemampuan menunjukkan kapasitas seseorang. Persepsi adalah bagaimana seseorang menafsirkan informasi secara seksama, sehingga perilakunya sesuai dengan yang diinginkan, sedang kepribadian adalah karakteristik seseorang yang meliputi pengetahuan, sikap, ketrampilan dan kemauan. Hal tersebut sebagaimana hasil penelitian Imbarwati (2009) meneliti tentang beberapa faktor yang berkaitan dengan penggunaan KB IUD pada peserta KB non IUD diKecamatan Pedurungan Kota Semarang. Penelitian ini menunjukkan bahwa persepsi memiliki hubungan yang positif dengan penggunaan jenis kontrasepsi, artinya semakin baik persepsi akseptor tentang kontrasepsi, maka perilakunya akan cenderung memakai kontrasepsi yang efektif.

\section{Hubungan Pengetahuan Responden Terhadap Penggunaan KB MKJP}


Berdasarkan uji Chi Square hubungan pengetahuan responden tentangKB MKJP dengan penggunaan KB MKJP didapatkan nilai $p$ value $=0,001 \quad(p<0,05)$. Maka Ho ditolak dan Haditerima dengan demikian disimpulkan bahwa ada hubungan pengetahuan responden tentang KB MKJP dengan penggunaan KB MKJP. Ada hubungannya dengan pengetahuan baik, cukup maupun kurang dari responden tentang penggunaan KB MKJP tetapi responden ada yang tidak memakai KB MKJP tersebut karena kurang pahamnya responden tentang $K B$ khususnya KB MKJP secara mendalam, kurangnya dukungan dari suami untuk menggunakan KB MKJP tersebut dan juga terpengaruh dari orang lain.

Semakin tinggi pendidikan maka akan jelas mempengaruhi seseorang dalam berpendapat berfikir dan bersikap, lebih mandiri dan rasional dalam mengambil keputusan dan tindakan. Hal ini akan mempengaruhi secara langsung seseorang dalam pengetahuannya akan orientasi hidupnya termasuk dalam merencanakan keluarganya (Gerungan, 1986, dalam penelitian Purba, 2008). Dengan demikian diharapkan semakin tinggi tingkat pendidikan semakin tinggi pula tingkat pengetahuan dan juga semakin meningkat pula penggunaan KB MKJP.

Hasil penelitian ini sejalan dengan penelitian tentang adanya hubungan pengetahuan dengan perilaku dalam penelitian Desiyana (2004) yang menyimpulkan bahwa pengetahuan peserta KB memiliki hubungan terhadap pemilihan kontrasepsi jangka panjang $(p$-value $=0,038)$, pada penelitian ini teknik pengambilan sampel yang digunakan adalah Proporsional Random Sampling.

\section{Hubungan Sikap RespondenTerhadap penggunaan KB MKJP}

Hasil analisisberdasarkan uji Chi square hubungan sikap responden tentangKB MKJP dengan penggunaan KB MKJP didapatkan nilai $p$ value $=0,002 \quad(p<0,05)$, sehingga Ho ditolak dan $\mathrm{Ha}$ diterima, maka ada hubungan sikap responden tentangKB MKJP dengan penggunaan KB MKJP. Berdasarkan hasilwawancara terhadap responden pada saat penelitian, mereka mengatakan kalau dalam menggunakan KB MKJP mereka diberi penjelasan akan pentingnya KB MKJP tersebut dan efek samping apabila mereka menggunakan KB MKJP tersebut, tetapi mereka secara tidak langsung masih takut apabila menggunakan KB MKJP tersebut karena mendapat informasi berdasarkan asumsi dari orang lain, maka dari itu akan mempengaruhi sikap mereka dalam menggunakan KB MKJP, semakin baik sikap responden tentangKB MKJP dengan penggunaan KB MKJP maka mereka cenderung menggunakan KB MKJP.

Sikap responden tentangKB MKJP dengan penggunaan KB MKJP merupakan satu langkah awal bagi responden dalam menyakini atau tidak menyakini penggunaan KB MKJP. Ketika ia setuju atau memiliki sikap baik terhadap penggunaan KB MKJP, maka ia akan cenderung berperilaku menggunakan KB MKJP. Demikian sebaliknya ketika ia tidak setuju atau memiliki sikap kurang baik terhadap penggunaan KB MKJP, maka ia akan cenderung berperilaku tidak menggunakan KB MKJP.

Hasil penelitian tentang adanya hubungan sikap dengan perilaku sesuai dengan hasil penelitian Desiyana (2004) yang menyimpulkan bahwa variabel sikap peserta $\mathrm{KB}$ memiliki hubungan yang bermakna terhadap pemilihan kontrasepsi jangka panjang.

\section{KESIMPULAN}

Berdasarkan hasil penelitian dan uraian pembahasan, maka dapat disimpulkan bahwa:

1. Sebagian besar responden memiliki pengetahuan cukup (60\%)tentang KB MKJP,sikap yang cukup (56\%) tentang penggunaan KB MKJP dan sebagian besar responden diketahui tidak menggunakan (55\%) KB MKJP.

2. Secara statistic terdapat hubungan yang bermakna yaitu: pengetahuan terhadap penggunaan KB MKJP dengan p-value $(0,001)<a \quad(0,05)$, dan sikap terhadap penggunaan KB MKJP p-value $(0,002)<\alpha$ $(0,05)$.

\section{SARAN}

Disarankan bagi instansi terkait perlunya adanya kerjasama lintas sector dalam upaya untuk meningkatkan pengetahuan dan sikap responden tentang keuntungan dan kelemahan penggunaan KB MKJP. Diharapkan dengan meningkatnya pengetahuan yang dimiliki oleh responden tentang KB MKJP, maka sikap responden dalam penggunaan kontrasepsi KB MKJP diharapkan menjadi lebih baik. Serta akan mempengaruhi meningkatnya angka penggunaan KB MKJP. 
Bagi peneliti yang akan meneliti dengan kajian dan subyek sejenis hendaknya meluaskan cakupan penelitiannya, misalnya dengan menambahkan faktor-faktor lain yang berhubungan dengan penggunaan KB MKJP seperti tingkat sosial ekonomi, pendidikan, dukungan suami, faktor budaya dan sebagainya sehingga dapat diketahui faktor apakah yang paling dominan berhubungan dengan penggunaan KB MKJP.

\section{DAFTAR PUSTAKA}

Affandi, B. 2011. Buku Panduan Praktis Pelayanan Kontrasepsi. Jakarta: Bina Pustaka Sarwono Prawirohardjo.

Badan Kependudukan dan Keluarga Berencana Nasional. 2011. Pedoman Pelayanan Keluarga 'Berencana Dalam Jaminan Persalinan Jampersal.BKKBN. Jakarta.

Badan Kependudukan dan KeluargaBerencana Nasional. 2017. Profil BKKBN. Jakarta.

Badan Pusat Statistik. 2013. Survei Demografi dan Kesehatan Indonesia (SDKI) Tahun 2012. Jakarta.

Desiyana, Anggraeni. 2004. Hubungan Karakteristik, Pengetahuan Dan Sikap Terhadap Pemilihan Kontrasepsi Pada Peserta Metode Kontrasepsi Jangka Panjang Di Kecamatan Pedurungan Kota Semarang. Skripsi.Fakultas Kesehatan Universitas Diponegoro. Semarang.

Dinas Pengendalian Penduduk Keluarga Berencana Pemberdayaan Perempuan dan Perlindungan Anak Kabupaten Banjar. 2017Laporan Bulanan Capaian KBTahun 2015-2017. DP2KBP3A. Kabupaten Banjar, Martapura.

Imbarwati. 2009. Beberapa Faktor Yang Berkaitan Dengan Penggunaan KB IUD Pada Peserta KB Non IUD di Kecamatan Pedurungan Kota Semarang. Tesis.Program Pasca Sarjana Universitas Diponegoro.Semarang.

Kementrian Kesehatan Republik Indonesia. 2012.Data dan Informasi Profil Kesehatan Indonesia2011. Kemenkes RI. Jakarta.

Kusumaningrum, R. 2009. Faktor Faktor Yang Mempengaruhi Pemilihan Konterasepsi Yang Digunakan Pada Pasangan Usia Subur (PUS). Karya Tulis IImiah. Fakultas Kedokteran UniversitasDiponegoro. Semarang.

Mubbarak dan Cahyatin. 2009. IImu Keperawatan Komunitas 2. CV Sagung Seto. Jakarta.
Niven, N. 2000. Psikologi Kesehatan : Pengantar Untuk Perawat dan Profesional Kesehatan Lain. EGC.Jakarta.

Purba, J, T. 2008. Faktor Faktor Yang Mempengaruhi Pemakaian Alat Konterasepsi Pada Isteri PUS Di Kecamatan Rabah Samo Kabupaten Rokan Hulu. Thesis. Pasca Sarjana Universitas Sumatera Utara. Medan.

Sugiyono. 2015. Metode Penelitian Pendidikan (Pendekatan Kuantitatif, Kualitatif dan $R \& D)$.Penerbit CV. Alfabeta: Bandung.

Wawan, A dan M, Dewi. 2010. Teori dan Pengukuran Sikap dan Perilaku Manusia. Yogyakarta. Nuha Medika 